EXTENDED REPORT

\title{
Efficacy of cyclo-oxygenase-2 inhibition by etoricoxib and naproxen on the axial manifestations of ankylosing spondylitis in the presence of peripheral arthritis
}

\author{
L Gossec, D van der Heijde, A Melian, D A Krupa, M K James, P F Cavanaugh, \\ A S Reicin, M Dougados
}

See end of article for authors' affiliations

Correspondence to: $\operatorname{Dr} L$ Gossec, Hôpital Cochin, Rhumatologie B,

Paris, France; laure. gossec@cch.aphp.fr

Accepted

17 February 2005

Published Online First

24 February 2005

\begin{abstract}
Objective: The combined efficacy of selective and non-selective cyclo-oxygenase-2 (COX-2) inhibition on the axial manifestations of ankylosing spondylitis (AS) in the presence or absence of chronic peripheral arthritis was evaluated.

Methods: In a post hoc subgroup analysis of a 6 week, randomised, double blind, placebo controlled trial, 387 patients with active axial AS were randomised to receive etoricoxib $90 \mathrm{mg}$ or $120 \mathrm{mg}$ once a day, naproxen $500 \mathrm{mg}$ twice daily, or placebo. Randomisation was stratified by the presence or absence of chronic peripheral arthritis. The primary outcome measure was the time weighted average change from baseline of spine pain intensity. Efficacy data from the three groups receiving active treatment (the NSAID/ COX-2 inhibitor group) were combined to improve precision. An analysis of covariance model was used to evaluate the effect of peripheral disease on treatment response.

Results: 93 patients were allocated to receive placebo and 294 to active treatment (naproxen or etoricoxib). The combined NSAID/COX-2 inhibitor group had a significant treatment response compared with the placebo group for all efficacy measures, both in patients with and without peripheral arthritis. A significantly greater difference in mean patient assessment of spine pain was found between active and placebo treatments in patients without compared with those with peripheral arthritis $(p=0.005$; $-32.5 \mathrm{~mm} v-17.0 \mathrm{~mm}$, respectively). Similar differences, although not statistically significant, were seen for other end points.

Conclusion: NSAIDs and COX-2 inhibitors have a clinically relevant symptomatic effect on axial AS irrespective of the presence of peripheral arthritis. In this exploratory analysis spinal improvement appeared to be greater in patients without peripheral disease.
\end{abstract}

$\mathrm{T}$ he group of diseases collectively labelled the spondyloarthropathies share different rheumatic manifestations; spinal symptoms predominate, but extraspinal joint disease (peripheral arthritis) and enthesopathic lesions also occur. ${ }^{1}$ Ankylosing spondylitis (AS) is the prototype of this group of interrelated disorders. Axial skeletal disease with sacroiliitis and spinal involvement is the hallmark of AS. Asymmetric peripheral arthritis is present in about $20-40 \%$ of patients with AS. The objectives for treatment of the axial involvement of AS are to reduce or prevent the deleterious clinical progression of the disease, which is characterised by inflammation and increasing ankylosis, leading to abnormal posture and decreased mobility.

Non-steroidal anti-inflammatory drugs (NSAIDs) acting via inhibition of cyclo-oxygenase-2 (COX-2) have been the cornerstone of treatment for patients with AS since the introduction of phenylbutazone. ${ }^{2}$ Most of the clinical trials involving NSAIDs clearly demonstrate substantial, quick relief of pain and inflammation. Because of this, the diagnosis of AS includes a therapeutic response to NSAID treatment within 48 hours or rapid relapse after treatment is stopped. ${ }^{3}$ However, it is unclear whether the therapeutic response to NSAIDs entails the axial symptoms, the peripheral arthritis, and/or the enthesopathic features. Nonselective NSAIDs have been shown to be efficacious in the treatment of the signs and symptoms of axial disease. However, clinical data from patients with peripheral arthritis are limited. Despite a lack of data based information, most clinical trials evaluating the symptomatic effect of NSAIDs in axial involvement of AS have excluded patients with concomitant peripheral arthritis. This exclusion was essentially based on the judgment of clinical experts that the clinical presentation comprising peripheral articular disease might interfere with the effect of NSAID treatment on the axial symptoms. From our personal clinical experience, before this post hoc analysis, we also wondered whether concomitant peripheral arthritis might influence the efficacy of COX-2 inhibition on the axial skeleton. However, this hypothesis has never been explored.

The successful relief of the pain and symptoms of AS with NSAIDs and COX-2 selective inhibitors strongly suggests a role for COX-2 inhibitors in the treatment of the disease. Etoricoxib, a COX-2 selective inhibitor, effectively relieves the pain and symptoms associated with rheumatoid arthritis, osteoarthritis, chronic low back pain, and gout. ${ }^{4}$ We recently conducted a two part 52 week controlled clinical trial in patients with AS, comparing the efficacy of daily etoricoxib 90 or $120 \mathrm{mg}$ with twice daily naproxen $500 \mathrm{mg}$, and placebo on the axial and peripheral manifestations of the disease. ${ }^{5}$ In

Abbreviations: ANCOVA, analysis of covariance; AS, ankylosing spondylitis; BASDAI, Bath Ankylosing Spondylitis Disease Activity Index; $\mathrm{Cl}$, confidence interval; COX-2, cyclo-oxygenase-2; DMARDs, disease modifying antirheumatic drugs; NSAIDs, non-steroidal antiinflammatory drugs; VAS, visual analogue scale 
that study, etoricoxib provided clinically better relief from the signs and symptoms of AS than both naproxen and placebo, and naproxen was better than placebo. Because in that trial, treatment assignment was stratified for the presence or absence of chronic peripheral arthritis or history of peripheral arthritis, in this analysis we took the opportunity to evaluate whether or not the effect of treatment on the axial skeleton was different in the presence or absence of peripheral arthritis.

This post hoc analysis aimed at exploring the axial treatment response resulting from etoricoxib and naproxen mediated COX-2 inhibition in AS patients with isolated axial disease, compared with those who also had peripheral arthritis.

\section{PATIENTS AND METHODS Patients}

All patients provided written informed consent before entering the study. The eligibility criteria for this study have been described previously. ${ }^{5}$ All patients were required to have radiographic evidence of sacroiliitis as defined by the modified New York criteria for the classification of AS. ${ }^{6}$ Inclusion criteria included regular NSAID intake, defined as at least 25 of the previous 30 days; NSAID or COX-2 inhibitor-specific washout period of 3-20 days before the baseline visit; a flare of the disease at baseline, defined by pain $\geqslant 40 \mathrm{~mm}$ (on a $100 \mathrm{~mm}$ visual analogue scale (VAS)), and by an increase in pain of at least $30 \%$ and minimum $12 \mathrm{~mm}$ compared with the screening visit; for patients taking disease modifying antirheumatic drugs (DMARDs), a stable dose for at least 3 months; and for patients taking low dose aspirin, a stable aspirin dose for at least 14 days.

Patients with acute peripheral disease, defined by the onset within 4 weeks before the study of active (painful or swollen) peripheral arthritis (except hip and shoulder), were excluded from the study. Patients with chronic peripheral arthritis were admitted to the study provided that the spine was the primary source of pain. Patients were classified as having "chronic peripheral arthritis" if they had painful or swollen peripheral arthritis of $>4$ weeks' duration, or a history of peripheral arthritis. A history of peripheral arthritis was an anamnestic element, which was recorded at study inclusion by the investigator, based on perusal of the patient's full medical chart and on patient recall. Patients with severe concomitant illness or with active inflammatory bowel disease were ineligible. Patients who had received corticosteroids or misoprostol during the previous month were also ineligible for the study.

Table 1 Patient demographics and accounting

\begin{tabular}{lll}
\hline & \multicolumn{2}{l}{ Peripheral arthritis } \\
\cline { 2 - 3 } & $\begin{array}{l}\text { Yes } \\
(\mathbf{n}=155)\end{array}$ & $\begin{array}{l}\text { No } \\
(\mathbf{n}=232)\end{array}$ \\
\hline Men, No (\%) & $115(74)$ & $186(80)$ \\
Age (years), mean (SD) & $43.8(13.9)$ & $43.5(10.4)$ \\
Age (years), range & $18-78$ & $21-74$ \\
Low back pain at rest, No (\%) & $152(98)$ & $229(99)$ \\
Limitation of lumbar spine*, No (\%) & $140(90)$ & $195(84)$ \\
Limitation of chest expansiont, No (\%) & $103(66)$ & $152(66)$ \\
Radiographic grade IV, No (\%) & $53(34)$ & $91(39)$ \\
Prior DMARD use, No (\%) & $77(50)$ & $81(35)$ \\
Prior corticosteroid use, No (\%) & $54(35)$ & $44(19)$ \\
Concomitant DMARD use, No (\%) & $49(32)$ & $37(16)$ \\
\hline
\end{tabular}

*Limitation of motion of the lumbar spine in both the sagittal and frontal planes; tlimitation of chest expansion relative to normal values corrected for age and sex.

\section{Study design}

The study was a multicentre, international, two part, randomised, double blind, parallel group, placebo and active comparator controlled study in patients with AS, conducted with in-house blinding, to evaluate the safety, tolerability, and efficacy of etoricoxib $90 \mathrm{mg}$ and $120 \mathrm{mg}$ once daily compared with naproxen $500 \mathrm{mg}$ twice daily and placebo. ${ }^{5}$ Treatment assignment was stratified by the absence or presence of chronic peripheral arthritis. The local ethics committee of each study centre approved this clinical trial. The work presented here is an analysis of the 6 week placebo controlled portion of the study. Because etoricoxib and naproxen both exert their analgesic and anti-inflammatory efficacy through inhibition of COX-2, we combined data from both of the groups receiving active treatment to increase the sample size and precision for a subgroup analysis in patients with and without peripheral arthritis.

\section{Study drugs}

Patients were randomly assigned (1:1:1:1) to receive placebo, etoricoxib $90 \mathrm{mg}$ or $120 \mathrm{mg}$ daily, or naproxen $500 \mathrm{mg}$ twice daily. Paracetamol (500 mg per tablet, maximum six tablets a day) was used as a rescue drug during the study, when needed. Corticosteroids and analgesics other than the assigned NSAID (naproxen) or COX-2 inhibitor (etoricoxib) were not allowed.

\section{Clinical end points used for analyses in this report}

This post hoc subgroup analysis based on the presence or absence of chronic peripheral arthritis was performed on the following end points:

- The prespecified primary end point for this analysis: patient assessment of spine pain (Bath Ankylosing Spondylitis Disease Activity Index (BASDAI) question 2)

- The pre-specified co-primary end points for the efficacy analysis (main analysis of the trial ${ }^{5}$ ): patient global assessment of disease activity (Bath Ankylosing Spondylitis Functional Index (BASFI))

- Post hoc end points: patient assessment of peripheral pain (BASDAI question 3); BASDAI stiffness (average of BASDAI questions 5 and 6); and BASDAI enthesopathy (question 4). ${ }^{78}$ The ASAS 20 responders were also determined post hoc: the percentage of patients experiencing symptomatic improvement of $\geqslant 20 \%$ and absolute improvement of $\geqslant 10$ units (on a scale of $1-100$ ) in three of the four outcome domains and no worsening by the same amount in the fourth domain (as recommended by the Ankylosing Spondylitis Working Group ${ }^{9}$ ). The four domains are patient global assessment, pain, function, and inflammation (morning stiffness). The ASAS20 criteria became available only after the primary study started and were therefore a post hoc end point.

\section{Statistical analyses}

These analyses combined patients treated with etoricoxib and naproxen into one active treatment group to maximise precision. Although etoricoxib was more efficacious than naproxen, effect sizes for patients with, compared with patients without, chronic peripheral arthritis were consistent for all active treatment groups; for example, patient assessment of spine pain, treatment effect comparing axial-peripheral: etoricoxib $90 \mathrm{mg}=-7.6 \mathrm{~mm}$; etoricoxib $120 \mathrm{mg}=-9.0 \mathrm{~mm}$; and naproxen $1000 \mathrm{mg}=-7.1 \mathrm{~mm}$ ). Thus it was considered that the best estimate of the difference in response in patients with and without peripheral arthritis would be provided by pooling the groups. In addition, the mechanism of the analgesic and anti-inflammatory actions of 
Table 2 Subgroup analysis of patient assessment of spine pain (100 mm VAS) based on the presence of peripheral arthritis or a history of peripheral arthritis

\begin{tabular}{|c|c|c|c|c|c|}
\hline \multirow[b]{3}{*}{$\begin{array}{l}\text { Peripheral arthritis } \\
\text { subgroup }\end{array}$} & \multicolumn{5}{|c|}{ Time weighted average change from baseline-weeks $0-6$} \\
\hline & \multicolumn{2}{|c|}{ Placebo } & \multicolumn{2}{|c|}{ Active treatment } & \multirow[b]{2}{*}{$\begin{array}{l}\text { Difference in LS } \\
\text { Mean (SE) }\end{array}$} \\
\hline & No & $\begin{array}{l}\text { LS } \\
\text { Mean (SE) }\end{array}$ & No & $\begin{array}{l}\text { LS } \\
\text { Mean (SE) }\end{array}$ & \\
\hline $\begin{array}{l}\text { Current arthritis } \\
\text { History of arthritis } \\
\text { None }\end{array}$ & $\begin{array}{l}14 \\
23 \\
56\end{array}$ & $\begin{array}{l}-15.3(6.0) \\
-18.8(4.6) \\
-10.0(3.0)\end{array}$ & $\begin{array}{r}44 \\
73 \\
175\end{array}$ & $\begin{array}{l}-29.6(3.4) \\
-37.4(2.6) \\
-42.5(1.7)\end{array}$ & $\begin{array}{l}-14.3(6.9) \\
-18.6(5.3) \\
-32.5(3.4)\end{array}$ \\
\hline
\end{tabular}

both agents is through inhibition of COX-2 and both demonstrated statistically significant improvements in efficacy compared with placebo.

Analyses were based on the time weighted average change from baseline for all observations across the 6 week treatment period. All patients who provided a measure at baseline and at least one measurement at a time after baseline were included in the analyses. Analysis of covariance (ANCOVA) was used for the subgroup analyses. Categorical factors in the ANCOVA model included treatment (COX-2 inhibitor group or placebo), peripheral arthritis (history or presence, or absence), and the interaction; and the baseline measure was included as a continuous covariate. The consistency of the treatment effects across subgroups of patients with and without chronic peripheral arthritis was assessed with the ANCOVA $f$ test for the interaction effect. Least squares mean change from baseline and the associated difference between the active group and placebo were computed, together with 95\% confidence intervals (CIs). Because this was a hypothesis-generating analysis, testing for multiplicity was not performed.

\section{RESULTS}

Table 1 presents the baseline characteristics of the patients. Forty per cent of the patients had chronic peripheral arthritis. In the group of patients with peripheral arthritis: 94/155 (61\%) had a previous history and 58/155 (37\%) currently had active arthritis of the hand, foot, elbow, ankle, and/or knee.

Table 3 Analysis of AS end points stratified by the presence/history or absence of chronic peripheral arthritis

\begin{tabular}{|c|c|c|c|c|c|}
\hline Peripheral arthritis & Treatment & No & $\begin{array}{l}\text { Baseline } \\
\text { Mean (SD) }\end{array}$ & $\begin{array}{l}\text { Change from baseline LS } \\
\text { Mean }(95 \% \mathrm{CI})\end{array}$ & Difference $(95 \% \mathrm{Cl})$ \\
\hline \multirow{2}{*}{\multicolumn{6}{|c|}{$\begin{array}{l}\text { Patient assessment of spine pain (VAS) } \\
\text { Treatment by strata interaction test, } p=0.005\end{array}$}} \\
\hline & & & & & \\
\hline Present & Placebo & 37 & $78.7(17.3)$ & $-17.5(-24.7$ to -10.3$)$ & \\
\hline Present & Active & 117 & $77.6(15.4)$ & $-34.5(-38.6$ to -30.4$)$ & $-17.0 *(-25.3$ to -8.7$)$ \\
\hline Absent & Placebo & 56 & $76.2(13.8)$ & $-10.0(-15.9$ to -4.1$)$ & \\
\hline Absent & Active & 175 & $77.7(14.5)$ & $-42.5(-45.8$ to -39.2$)$ & $-32.5^{*}(-39.2$ to -25.7$)$ \\
\hline \multicolumn{6}{|c|}{ Patient assessment of peripheral pain-BASDAl question No 3 (VAS) } \\
\hline \multicolumn{6}{|c|}{ Treatment by strata interaction test, $p=0.45$} \\
\hline Present & Placebo & 37 & $61.8(27.0)$ & $0.9(-5.9$ to 7.6$)$ & \\
\hline Present & Active & 117 & $61.2(27.5)$ & $-16.4(-20.3$ to -12.6$)$ & $-17.3^{*}(-25.0$ to -9.6$)$ \\
\hline Absent & Placebo & 56 & $45.4(31.9)$ & $-5.5(-11.0$ to -0.1$)$ & \\
\hline Absent & Active & 175 & $43.5(31.5)$ & $-26.6(-29.7$ to -23.5$)$ & $-21.1^{*}(-27.4$ to -14.8$)$ \\
\hline \multirow{2}{*}{\multicolumn{6}{|c|}{ Patient assessment of enthesopathy-BASDAl question No 4 (VAS) }} \\
\hline & & & & & \\
\hline Present & Placebo & 37 & $59.9(27.9)$ & $-6.5(-13.3$ to 0.4$)$ & \\
\hline Present & Active & 117 & $59.1(27.2)$ & $-21.3(-25.2$ to -17.5$)$ & $-14.9^{*}(-22.7$ to -7.0$)$ \\
\hline Absent & Placebo & 56 & $51.8(28.3)$ & $-7.3(-12.9$ to -1.8$)$ & \\
\hline Absent & Active & 175 & $51.7(29.1)$ & $-27.6(-30.8$ to -24.5$)$ & $-20.3^{*}(-26.7$ to -13.9$)$ \\
\hline \multicolumn{6}{|c|}{ Patient global assessment of disease activity (VAS) } \\
\hline \multicolumn{6}{|c|}{ Treatment by strata interaction test, $p=0.32$} \\
\hline Present & Placebo & 37 & $66.5(21.8)$ & $-3.3(-10.0$ to 3.5$)$ & \\
\hline Present & Active & 117 & $64.8(23.3)$ & $-22.0(-25.7$ to -18.2$)$ & $-18.7^{*}(-26.4$ to -10.9$)$ \\
\hline Absent & Placebo & 56 & $62.8(20.5)$ & $-4.3(-9.7$ to 1.2$)$ & \\
\hline Absent & Active & 175 & $63.4(20.3)$ & $-28.0(-31.1$ to -24.9$)$ & $-23.7^{*}(-30.0$ to -17.5$)$ \\
\hline \multirow{2}{*}{\multicolumn{6}{|c|}{ Bath Ankylosing Spondylitis Functional Index (VAS) }} \\
\hline & & & & & \\
\hline Present & Placebo & 37 & $55.2(29.8)$ & $-3.5(-9.2$ to 2.3$)$ & \\
\hline Present & Active & 117 & $58.3(23.8)$ & $-14.9(-18.2$ to -11.7$)$ & $-11.4^{*}(-18.0$ to -4.8$)$ \\
\hline Absent & Placebo & 56 & $53.4(25.2)$ & $-5.1(-9.8$ to -0.4$)$ & \\
\hline Absent & Active & 175 & $53.7(23.3)$ & $-20.3(-22.9$ to -17.6$)$ & $-15.2^{*}(-20.6$ to -9.8$)$ \\
\hline \multirow{2}{*}{\multicolumn{6}{|c|}{$\begin{array}{l}\text { Morning stiffness - mean of BASDAl questions } 4 \text { and } 5 \text { (VAS) } \\
\text { Treatment by strata interaction test, } p=0.45\end{array}$}} \\
\hline & & & & & \\
\hline Present & Placebo & 37 & $61.8(26.0)$ & $-5.7(-12.4$ to 1.0$)$ & \\
\hline Present & Active & 117 & $61.8(25.4)$ & $-24.4(-28.1$ to -20.6$)$ & $-18.7^{*}(-26.4$ to -11.0$)$ \\
\hline Absent & Placebo & 56 & $65.0(21.4)$ & $-6.2(-11.6$ to -0.7$)$ & \\
\hline Absent & Active & 175 & $62.6(23.7)$ & $-28.7(-31.8$ to -25.6$)$ & $-22.5^{*}(-28.8$ to -16.2$)$ \\
\hline
\end{tabular}

*Difference from placebo is significant at $p<0.05$. 


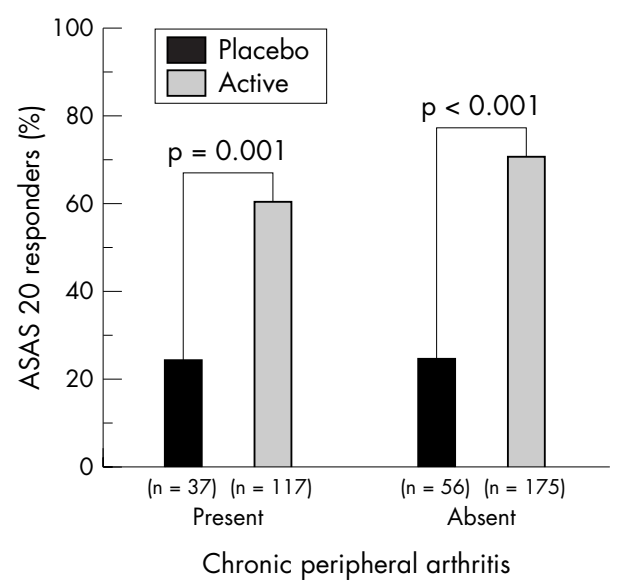

Figure 1 AS patients with and without peripheral arthritis who demonstrated symptomatic improvement based on ASAS 20 criteria. Note that the treatment by strata interaction did not reach significance for the ASAS 20 end point $(p=0.52)$.

Previous or current arthritis was reported at other sites by $3 / 155(2 \%)$ of the patients in the group with peripheral arthritis. Two of these patients had arthritis of the hip or shoulder, or both. Inclusion of these two patients in the analysis did not change the results obtained. Most of the patients were men, under the age of 50, had low back pain, had limitations of the lumbar spine and chest expansion, and $37 \%$ had radiographic stage IV AS. ${ }^{6}$ Stage IV disease is characterised by radiographic evidence of spinal involvement in $>2$ spinal segments (13-19 vertebrae-that is, $50-80 \%$ of the spine). The two groups appeared to be well balanced, except for a higher percentage of concomitant DMARD and prior corticosteroid use in the group with peripheral arthritis.

A significant treatment by peripheral arthritis strata interaction was only detected for patients' assessment of spine pain (table 2). Specifically, there was a greater difference in spinal pain response between the active and placebo groups in AS patients without (-32.5 mm; 95\% CI -39.2 to -25.7 ) compared with AS patients with chronic peripheral arthritis $(-17.0 \mathrm{~mm}$; $95 \%$ CI -25.3 to -8.7$)$. Similar differences between patients with and without peripheral arthritis were also seen for other end points, including the ASAS 20, but these did not reach significance (table 3). These differences were mainly related to a lower efficacy of NSAIDs in patients with peripheral arthritis, rather than a higher placebo effect (table 3). Statistically significant symptomatic improvement after active treatment was seen for all primary and post hoc end points (table 3 ), including the ASAS 20 responder criteria for symptomatic improvement (fig 1). Except for patients' assessment of spine pain, the improvement from baseline in the placebo group was greatest in the group without peripheral arthritis. Inclusion of previous or current use of DMARDs in the interaction model as covariates provided a similar significant treatment by peripheral arthritis strata interaction for patients' assessment of spine pain.

\section{DISCUSSION}

Most clinical studies of patients with AS have excluded those with a history of peripheral arthritis. In this study we enrolled AS patients with and without peripheral disease provided that the spine was the primary source of pain. We used validated clinical response criteria ${ }^{9}$ to demonstrate that inhibition of COX-2, in the combined etoricoxib and naproxen groups, provided significant clinical efficacy in AS patients with and without peripheral arthritis. The treatment responses observed across the clinical end points for the combined active treatment group compared with placebo treatment are in agreement with those seen in other trials of NSAIDs in patients with AS. ${ }^{9}$ However, the magnitude of these responses was greater in patients without chronic peripheral arthritis or a history of peripheral arthritis. Although a significant difference in treatment effect among those with compared with those without peripheral arthritis was only seen for the primary end point of spinal pain, other end points demonstrated qualitatively similar differences, suggesting an overall difference in response between the two patient subgroups. Furthermore, it is not surprising that the differential effect should be clearest for spinal pain because the other end points are global AS end points.

One explanation might be that in patients with chronic peripheral arthritis, the painful sensation of the peripheral joints interferes with the spinal pain. However, the results are similar for patients with chronic arthritis and with a history of arthritis.

The pathophysiological mechanisms responsible for the difference in treatment response between patients with and without peripheral arthritis have yet to be elucidated. These differences may reflect quantitative differences in the degree of inflammation, qualitative differences in the production of biochemical mediators which drive the inflammatory processes in these two subgroups, or perceptual differences in the level and extent of pain. To date, neither radiographic nor pathological studies have conclusively identified differences in the axial skeletal manifestations of disease in patients with and without peripheral arthritis that might explain our findings. It is known that patients both with and without peripheral arthritis have enthesopathies and both patient subgroups have synovitis of their synarthrodial joints. It is also known that COX-2, a rate limiting enzyme in the prostaglandin biosynthetic pathway, is highly expressed in the synovium of patients with AS. Moreover, in patients with AS the level of COX-2 in synovial tissues seems to be proportional to the severity of disease. ${ }^{10}$ To date, studies examining the relative expression of prostaglandins in peripheral compared with axial joints or in patients with peripheral arthritis compared with those without peripheral arthritis have not been performed.

Of interest, although not measured in this study, historical data suggest that circulating levels of acute phase reactants are higher in AS patients with peripheral arthritis, ${ }^{11}{ }^{12}$ than in those without. This might reflect quantitative differences in the level of inflammation in these patients, or qualitative differences in the production of cytokines (or other inflammatory mediators) that drive this inflammation. Because it is known that NSAIDs and COX-2 selective inhibitors have little or no effect on acute phase reactants, the possibility exists that there are additional mediators of inflammation in patients with peripheral arthritis that are not well attenuated by cyclo-oxygenase inhibition.

Also of interest in the interpretation of these exploratory findings is the relative contribution of enthesopathy compared with synovitis in the manifestation of spinal pain. Both are inflammatory processes but one might be more driven by prostanoids than the other. This field is worthy of further study.

In conclusion, both NSAIDs and COX-2 selective inhibitors offer an effective treatment for AS patients with and without peripheral arthritis, but the relative treatment effects seem to be greater in those without a history of arthritis or chronic peripheral arthritis. The greater effects of treatment in patients without peripheral arthritis suggest that such patients may have different disease processes which are more NSAID responsive than those in patients with peripheral arthritis. It also suggests that the pathophysiology of AS warrants further 
study, particularly of disease mediators and their relative contribution in distinct patient groups.

\section{ACKNOWLEDGEMENTS}

We thank the following members of the Ankylosing Spondylitis Study Group for their contributions to this study. A McKay Brabham; Joel C Silverfield; Peter A Holt; Raimon SanMartí-Sala; Jordi Gratacos; Eduardo Collantes Estevez; Pedro Zarco; Juan Carlos Torre Alonso; Wolfgang Ebner; Friedrich Hasler; Urs Moser; William B Gruhn; Marc Miller; Ruben Burgos; Mario Cardiel; Cesar Remus; Kenneth M Nies; Jose Maldonado-Cocco; Arthur L Weaver; Sol Villegas de Morales; Herbert SB Baraf; John Edmonds; Mary Bell; Piyush Patel; Paul Peloso; Hector Gatica; Denis Choquette; Alfonso Verdejo; Henning Zeidler; Jurgen Braun; Jan Brandt; Antonio Da Silva; George Struthers; Andrei Calin; Roger Sturrock; Maria Tuna; Ruben Mantilla; Christopher Lyddell; Anne Marie Halland; Tore Kvien; David G Borenstein; Michael Schiff; Peter H Stein. We would also like to thank James Bolognese and Ned Braunstein of Merck Research Laboratories for their critical review of this manuscript. This work was supported by Merck Research Laboratories, Rahway, NJ, USA.

\section{Authors' affiliations}

L Gossec, M Dougados, René Descartes University, Cochin Hospital, Rheumatology B Department, Paris, France

D van der Heijde, University Hospital Maastricht, Maastricht, The Netherlands

A Melian, D A Krupa, M K James, P F Cavanaugh, A S Reicin, Merck Research Laboratories, Rahway, NJ, USA

Reprint requests to: Professor M Dougados, hôpital Cochin, Rhumatologie B, 27 rue du Faubourg Saint-Jacques, 75014 Paris, France; maxime.dougados@cch.aphp.fr

\section{REFERENCES}

1 Dougados M, van der Heijde D. Ankylosing spondylitis: how should the disease be assessed? Best Pract Res Clin Rheum 2002;16:605-18.

2 Ward MM, Kuzis S. Treatments used by patients with ankylosing spondylitis: comparison with treatment preferences of rheumatologists. J Clin Rheumatol 1999;5:1-8.

3 Amor B, Dougados M, Listrat V, Menkes CJ, Roux H, Benhamou C, et al. Are classification criteria for spondylarthropathy useful as diagnostic criteria? Rev Rhum Engl Ed 1995;62:10-15.

4 Matsumoto AK, Cavanaugh PF Jr. Etoricoxib. Drugs Today 2004:40:395-414.

5 van der Heijde D, Baraf HSB, Ramos-Remus C, Calin A, Weaver AL, Schiff M, et al. Evaluation of the efficacy of etoricoxib in ankylosing spondylitis: results of a 52-week randomized controlled study. Arthritis Rheum 2005:52:1205-15.

6 van der Linden S, Valkenburg HA, Cats A. Evaluation of diagnostic criteria for ankylosing spondylitis. A proposal for modification of the New York criteria. Arthritis Rheum 1984;27:361-8.

7 Garrett S, Jenkinson T, Kennedy LG, Whitelock H, Gaisford P, Calin A. A new approach to defining disease status in ankylosing spondylitis: the Bath Ankylosing Spondylitis Disease Activity Index. J Rheumatol 1994;21:2286-91.

8 Calin A, Garrett S, Whitelock H, Kennedy LG, O'Hea J, Mallorie P, et al. A new approach to defining functional ability in ankylosing spondylitis: the development of the Bath Ankylosing Spondylitis Functional Index. J Rheumatol 1994;21:2281-5

9 Anderson JJ, Baron G, van der Heijde D, Felson DT, Dougados M. Ankylosing Spondylitis Assessment Group preliminary definition of short-term improvement in ankylosing spondylitis. Arthritis Rheum 2001:44:1876-86.

10 Siegle I, Klein T, Backman JT, Saal JG, Nüsing RM, Fritz P. Expression of cyclooxygenase-1 and cyclooxygenase- 2 in human synovial tissue. Arthritis Rheum 1998;41:122-9.

11 Claudepierre P, Rymer JC, Authier FJ, Allanore Y, Larget-Piet B, Gherardi R, et al. A relationship between TGF- $\beta 1$ or IL- 6 plasma levels and clinical features of spondyloarthropathies. Br J Rheumatol 1997;36:400-1.

12 Spoorenberg A, van der Heijde D, de Klerk E, Dougados M, de Vlam K, Mielants $\mathrm{H}$, et al. Relative value of erythrocyte sedimentation rate and $\mathrm{C}$ reactive protein in assessment of disease activity in ankylosing spondylitis. J Rheumatol 1999;26:980-4. 